\title{
PRODUÇÃO DO CONHECIMENTO SOBRE A FORMAÇÃO DOS PROFESSORES DO CAMPO NO BRASIL: TESES E ANTÍTESES1
}

\author{
Joelma de Oliveira Albuquerque ${ }^{2}$
}

\section{RESUMO}

Os elementos apresentados no texto são parte da análise de 433 estudos em nível de teses e dissertações a partir das expressões exatas Educação do campo, Educação rural, Escola rural e Educação no campo, cujos resultados fornecem a base deste texto, resultante de uma tese de doutorado. $\mathrm{O}$ objetivo é explicitar a crítica realizada às concepções sobre a formação de professores, apontando possibilidades frente à relação que se estabelece com a categoria modo de produção. As análises revelaram a tendência dominante da concepção idealista expressa na perspectiva do professor reflexivo, na qual se defende uma formação com base em conteúdos e saberes do e para o meio rural, pautados no cotidiano e da identidade cultural dos sujeitos das áreas rurais, ou seja, predomina nas teses e dissertações a perspectiva do professor reflexivo. Por outro lado as antíteses revelaram que a consideração dos elementos concretos do modo de produção e sua expressão no campo indicam a possibilidade de avanço na compreensão acerca do que vem se denominando de antagonismo entre campo e cidade, que veicula a ideia de que trabalhadores do campo e da cidade são diferentes, e portanto, devem ter formações específicas, baseadas nas suas culturas, nos seus cotidianos. Em nossa análise, este é o ponto nevrálgico que explica a formação que é proporcionada para os trabalhadores do campo e da cidade. A formação dos professores tem no modo de produção sua base concreta, cuja consideração é o primeiro ato para trazer a formação ao mundo real dos trabalhadores do campo.

Palavras-Chaves: Produção do conhecimento; formação de professores do campo; modo de produção.

\section{PRODUCTION OF KNOWLEDGE ABOUT THE EDUCATION OF TEACHERS OF THE FIELD IN BRAZIL: THESIS AND ANTITHESIS}

\begin{abstract}
The elements presented in the text are part of the analysis of 433 studies on the level theses and dissertations from the exact expressions countryside education, rural education, rural school and education in the countryside, the results provide the basis of this text, resulting in a thesis doctorate. The aim is to explicit the critical conducted to conceptions of teacher education, pointing possibilities in the relationship that is established with the category mode of production. The analysis revealed the dominant trend of the idealist conception expressed in the perspective of the reflective teacher, in which endorse an education based on content and knowledge to and from rural areas, guided in daily life and cultural identity of the persons in rural areas, namely, predominates in theses and dissertations the perspective from reflective teacher. However, the antitheses revealed that consideration of concrete elements in the mode of production, and its expression in the countryside indicate the possibility of advancement in understanding of what has been the antagonism between town and countryside, which conveys the idea that field workers and city are different, and therefore must have specific education, based on their cultures in their daily lives. In our analysis, this is the main point that explains the education that is provided for workers in the countryside and the city. The teacher education in production mode has its concrete base, whose consideration is the first act to bring the education to the real world of rural workers.
\end{abstract}

Key Words: knowledge production; teacher education field; production mode. 


\section{Introdução}

Os elementos que apresentamos neste texto são parte da crítica realizada através do nosso estudo de doutorado, intitulado Crítica à produção do conhecimento sobre a educação do campo no Brasil: teses e antíteses sobre a educação dos trabalhadores no início do século XXI, desenvolvido a partir da análise de 433 estudos em nível de teses e dissertações a partir das expressões exatas Educação do campo, Educação rural, Escola rural e Educação no campo, cujos resultados fornecem a base deste texto. O objetivo é explicitar a crítica realizada à produção do conhecimento sobre a educação dos trabalhadores do campo no Brasil, especificamente às concepções sobre a formação de professores, apontando possibilidades frente à relação que se estabelece com a categoria modo de produção. Iniciamos o texto expondo os pressupostos teóricos da crítica e os procedimentos metodológicos adotados. Em seguida, apresentamos o conteúdo da crítica, e por fim uma síntese indicativa de possibilidades investigativas acerca da educação dos trabalhadores do campo com base na categoria modo de produção.

O crescente interesse dos pesquisadores brasileiros pela problemática da educação dos trabalhadores do campo indica a necessidade de análises críticas criteriosas que nos permitam indagar que tipo de pesquisa está se realizando, sua qualidade e utilização, onde é realizada, em que condições, o tipo de conteúdos que desenvolve, temas escolhidos, sua relação com as exigências e necessidades regionais e nacionais, sua contribuição para a construção de novas teorias e para o desenvolvimento de novas pesquisas, tarefas estas atribuídas aos estudos epistemológicos. (SÁNCHEZ GAMBOA, 2007).

Esta necessidade se impõe à educação dos trabalhadores do campo uma vez que a mesma se situa no contexto da luta de classes, pautada nas necessidades históricas da classe trabalhadora em luta, a exemplo da Educação do Campo. De acordo com o método de conhecimento do real que nos aproximamos - o materialista histórico dialético -, as relações entre as características lógicas das pesquisas e suas determinações históricas tem sua compreensão baseada no fato de que a análise da lógica de um determinado fenômeno na sua forma mais desenvolvida é a chave para a análise do processo histórico de desenvolvimento deste fenômeno. (DUARTE, 2003, p.68). Segundo Duarte (2003) a análise só se realiza de forma verdadeiramente esclarecedora do objeto se for apoiada em uma perspectiva crítica, caso contrário, legitima-se apenas o estado atual e não se atinge o objetivo de compreender melhor as possibilidades de transformação da situação estudada. (Idem, p.71).

Para caracterizar a categoria 'crítica', recuperamos Enguita (1985) que aponta a necessidade de delimitarmos uma crítica da educação, antes de desenvolvermos uma teoria da educação. O autor aponta que esta crítica deve observar alguns critérios. Enguita (1985) aponta que uma crítica da educação: em primeiro lugar, se trata de uma crítica, algo construído por oposição ( la contra). Segundo o autor, não é possível encontrar em Marx a intenção de elaborar um modelo de educação a partir do qual seria medida a educação existente ou que seria preparada a educação do futuro. Esta não é o resultado de um plano alternativo de educação, nem tampouco a educação de um plano alternativo de sociedade, ambos inexistentes. (ENGUITA, 1985, p. 85-86, tradução nossa). Em segundo lugar, a crítica tem que ser materialista, e não a partir de possíveis ideais educativos ou eventualmente, de uma determinada ideia definida de homem e das suas necessidades, mas sim o homem que vive dentro de uma dada sociedade e em um dado momento histórico, dos quais emergem necessidades, não limitadas somente ao homem, mas sim necessidades históricas e sociais, entre as quais estão as necessidades no aspecto educativo. (Ibdem, p.86, tradução nossa). Em terceiro lugar, a crítica não deve perder em momento algum a 
visão de totalidade - histórica e social, devendo abarcar todas as vias através das quais se produz e reproduz a consciência social e individual. As instituições educativas em sua existência separada e autônoma, não serão tomadas como instituições naturais, mas sim como um produto histórico e social que só pode ser compreendido dentro do transcurso da totalidade da qual faz parte, ou seja, como produto de um estágio de desenvolvimento social. (Ibdem, tradução nossa). Em quarto lugar, considerando que a educação é inculcação de uma série de valores, ideias, atitudes etc., predeterminados, o objetivo da crítica marxiana não é o de opor a estes valores outros distintos e alternativos, mas sim (...) mostrar la relación entre los valores educativos e las condiciones materiales que les subyacen y contribuir a la destrucción de tales bases materiales, quando fizerem parte de um estágio histórico esgotado (Ibdem). Em quinto lugar, se a ideologia e as superestruturas sociais (dentre elas o aparato educativo) encontram sua explicação na crítica à economia política, a própria análise econômica terá muito a dizer ao situar a educação dentro do processo de produção e reprodução do capital e do valor, sobre o papel da educação no processo geral de produção social, seu surgimento enquanto necessidade social (não meramente individual), e as potencialidades da antítese entre as necessidades criadas e as realmente satisfeitas no terreno da educação. (Idem, 87, tradução nossa). Em sexto lugar, há que se compreender a valoração crítica da educação realmente existente, das ideias dominantes sobre a educação, e de outros aspectos da vida social que contribuem para os sucessos ou fracassos no campo da educação. Esta valoração crítica não se deterá simplesmente e será satisfeita na enumeração de obstáculos que a organização da sociedade põe na realização de qualquer ideal educativo que pretenda transcendê-la, mas deverá, sobretudo, tratar de localizar as tendências já existentes dentro da própria sociedade atual que permitam prever e delimitar o que serão, uma vez livres de entraves, as tendências da educação do futuro. (Ibdem, tradução nossa).

Com base nos parâmetros apresentados, em especial na quinta indicação, consideramos que para desenvolver este aspecto da crítica na produção do conhecimento sobre a educação dos trabalhadores do campo, é imprescindível nos valermos da categoria 'modo de produção' e sua expressão no campo, de forma a identificar tendências educativas e suas respectivas antíteses frente ao contexto do mercado de terras, do modelo produtivo do agronegócio, os quais exigem a propagação do latifúndio com consequente expropriação de terras dos trabalhadores e sua submissão ao capital enquanto força de trabalho temporária e desregulamentada. (ROSSET, 2004).

Foi com base nestes parâmetros que desenvolvemos a crítica à produção científica acerca da formação do trabalhador do campo, na qual está incluída a crítica às concepções de formação de professores do campo. As fontes selecionadas para tal análise foram teses e dissertações produzidas entre os anos de 1987 e 2009, cujas informações estavam disponíveis no banco de teses e dissertações da Capes (Coordenação de Aperfeiçoamento de Pessoal do Ensino Superior). Para a busca no portal da CAPES nos valemos das expressões exatas Educação do Campo (com 125 estudos localizados - 28 teses e 97 dissertações, produzidas a partir de 2003); Educação no Campo (com 25 estudos localizados, sendo 5 teses e 20 dissertações produzidas a partir de 1992); Educação rural (com 161 estudos localizados, sendo 24 teses e 137 dissertações, produzidas desde 1987 até 2009); e Escola rural (com 122 estudos localizados, dos quais, 11 são teses e 111 são dissertações, produzidas desde 1987 até 2009), totalizando 433 estudos identificados através dos respectivos resumos, dentre os quais 365 são de dissertações, e 68 são de teses.

As informações coletadas foram sistematicamente analisadas na busca de regularidades acerca das problemáticas abordadas. Desta forma identificamos: 1) Teoria Educacional; 2) Teoria Pedagógica; 3) Políticas públicas; 4) Formação de professores; 5) 
outras temáticas relacionadas com a educação no meio rural. No interior de cada um destes grupos, foram identificadas teses hegemônicas e antíteses. A análise aqui exposta diz respeito ao grupo de estudos quatro (4), que tem por temática a formação de professores, a partir do qual expomos as concepções de formação de professores do campo e as relações que estabelecem com a categoria modo de produção.

Concepções de formação de professores na pesquisa sobre a educação dos trabalhadores do campo: crítica à tese hegemônica e suas consequências para a formação humana

Conforme demonstramos no item anterior, o 'Grupo 4' trata das problemáticas acerca da formação de professores, e reuniu 37 estudos, grupo bastante reduzido se considerarmos o 'Grupo 2' sobre a teoria pedagógica, com 198 trabalhos (mais de cinco vezes maior que o 'Grupo 4'). O grupo de estudos sobre a formação de professores da Educação do Campo é o maior com 17, quando comparado com os três estudos acerca da escola rural, os 14 sobre educação rural, os três em educação no campo.

Quanto às teses hegemônicas no conjunto da produção, predomina a defesa da escola/educação com conteúdos e saberes do e para o meio rural, pautados no cotidiano e na identidade cultural dos sujeitos das áreas rurais em todas as temáticas. Dos 433 estudos identificados, são 236 (cerca de 55\%) que veiculam esta tese de fundo. Especificamente sobre a formação de professores (Grupo 4), 21 dos 37 estudos, ou seja, cerca de $57 \%$ dos estudos deste grupo se pautam nesta tese.

No que diz respeito à formação do professor, esta tese se expressa na defesa da formação com conteúdos e saberes do e para o meio rural, pautados no cotidiano e da identidade cultural dos sujeitos das áreas rurais. Nesta os sentidos e significados construídos pelo professor na sua prática cotidiana determinam a organização do trabalho pedagógico. $\mathrm{O}$ aspecto marcante é a atribuição ao professor a responsabilidade de construir sua própria formação, seu próprio caminho profissional e a superação das carências estruturais da escola por meio de sua prática cotidiana, conforme pode ser observado nos extratos: a professora construiu ao longo de sua carreira uma pratica pedagógica própria, buscando alternativas adequadas aos seus propósitos educacionais bem como as suas limitações e carência daquela realidade; a professora conseguiu superar as deficiências de material e de assistência pedagógica, obtendo êxito apesar de todos os obstáculos comuns a todas as escolas da zona rural; a importância de olharmos a educação do campo em um contexto onde seus sujeitos sejam responsáveis pelo seu projeto educacional, considerando as especificidades circunscritas no seu espaço, bem como na vivência de seus sujeitos, como aspectos relevantes para o exercício da cidadania; o professor (monitor) da EFA possui uma gama diversificada de saberes. Aponta a necessidade da valorização dos saberes da prática e do reconhecimento do docente como sujeito que discute, propõe e organiza sua própria formação e de seus futuros pares; a escola é um lugar onde ocorre a formação continuada dos professores e o cotidiano escolar é um agente de (trans)formação da prática educativa.

Buscando explicações sobre o significado desta tese, nos valemos das contribuições de Duarte (2003) ao discutir a questão epistemológica que está no centro do debate sobre a formação de professores, a saber, a epistemologia da prática profissional. Para tanto, o autor recupera elementos teóricos apresentados por Maurice Tardif, Philipe Perrenoud, Isabel Alice Lelis, António Nóvoa, Angel Pérez Gómez e Donald Schön acerca desta questão epistemológica, os quais foram veiculados em periódicos e livros de grande circulação nacional. A tese principal defendida por estes autores parte de uma constatação 
apresentada por Tardif (2000 apud DUARTE, 2003), na qual os cursos de formação no âmbito da universidade não estariam dando conta adequadamente da formação profissional por estarem centrados no saber acadêmico, teórico, científico. A proposta de Tardif aponta Duarte, é que as pesquisas em âmbito educacional se voltem quase que inteiramente para a investigação dos saberes que os professores utilizariam em seu cotidiano profissional. (DUARTE, 2003, p.603).

Constatamos que este 'fenômeno' se passa também na produção do conhecimento sobre a educação dos trabalhadores do campo. É grave o fato de que, ao considerar que o professor se forma em seu cotidiano e deste emergem os seus saberes profissionais, de nada vale pesquisar quais são estes saberes, uma vez que eles não podem ser referência para outros professores, por serem considerados específicos de determinada realidade escolar. $\mathrm{O}$ avanço da ciência desta forma é seriamente comprometido, havendo uma abordagem simples ao problema (SÁNCHEZ GAMBOA, 2007) da formação de professores, o que resulta em uma resposta igualmente simples: sim, os professores constroem saberes através de sua prática cotidiana, os quais não importam para a comunidade científica, pois dizem respeito somente àquela realidade investigada.

Duarte ao analisar a questão da epistemologia da prática profissional por meio das elaborações de Tardif, demonstra que para este, os saberes profissionais dos professores são caracterizados como saberes temporais, plurais, heterogêneos, personalizados, situados e, por fim, como saberes que carregam as marcas do ser humano em consequência de o objeto do trabalho docente ser construídos por seres humanos. (TARDIF, 2000, p.13-14 apud DUARTE, 2003, p.604). Estes saberes voláteis deveriam, portanto, ocupar o centro da formação de professores, em nome do que se dá um valor maior à pesquisa acerca dos saberes profissionais em detrimento da pesquisa no campo das disciplinas acadêmicas. Para Duarte (2003), os argumentos de Tardif conduzem à conclusão sobre a irrelevância ou até mesmo sobre o caráter prejudicial do saber científico/teórico/acadêmico tanto na formação de professores como na pesquisa educacional. (Idem, p.605-606). Verificamos em relação à educação dos trabalhadores do campo que esta ideia torna-se uma saída aparentemente viável frente a uma realidade na qual a maioria esmagadora dos professores não tem sequer o direito de cursar a formação inicial. Esta concepção é ainda mais devastadora se considerarmos a precariedade da educação em nosso país, em especial, do trabalho dos professores, frente ao que esta concepção torna-se uma ilusão a se agarrar.

Nos ajuda na reflexão ainda, a crítica tecida por Duarte à concepção epistemológica do professor reflexivo por meio das elaborações de Philipe Perrenoud. Segundo Perrenoud, se a universidade deseja formar professores reflexivos então ela deveria abandonar quatro ilusões sobre "o estado dos saberes teóricos e sua pertinência para fundar uma prática profissional": a ilusão cientificista; a ilusão disciplinar, a ilusão da objetividade, e a ilusão metodológica. (PERRENOUD, 2002, p. 89-105 apud DUARTE, 2003, p.606). Cabe colocar que atualmente no Brasil, vem crescendo a reivindicação dos movimentos de luta social pela formação dos professores que trabalham no meio rural, luta esta contrariada pela concepção de Perrenoud, dado que, se os professores já estão atuando nas escolas, e que estas já lhes dão subsídios para sua 'autoformação', para que então pensar em formação superior para os professores do campo?

A produção científica apresenta, portanto, subsídios teóricos que vem sendo incorporados à ações concretas que pretendem elevar a formação dos professores que atuam nas escolas do campo. Um exemplo é o programa "Licenciatura em Educação do Campo" (PROCAMPO/SECADI/MEC) (Secretaria de Educação Continuada, Alfabetização, Diversidade e Inclusão do Ministério da Educação). 
O Procampo é um programa de apoio a implementação de cursos regulares de Licenciatura em Educação do Campo nas Instituições Públicas de Ensino Superior de todo o país, voltados especificamente para a formação de educadores que atuam em experiências alternativas em Educação do Campo das Redes Públicas de Ensino para a docência nos anos finais do ensino fundamental e ensino médio nas escolas rurais. O Curso é ofertado em regime de alternância (Tempo Escola e Tempo Comunidade). (...) A proposta curricular do curso da licenciatura esta referenciada na realidade do campo. Os componentes curriculares são organizados por áreas do conhecimento: Linguagens; Ciências Humanas e Sociais; Ciências da Natureza e Matemática e Ciências Agrárias. O regime de alternância entre Tempo/Escola-Curso e Tempo/ Comunidade-Escola do Campo permitem arranjos que garantem o ingresso e permanência dos profissionais que atuam nas escolas do campo sem a necessidade de deixar de viver no campo. (BRASIL, Ministério da Educação, PDE, ...).

É possível verificar as concepções aqui criticadas nos fundamentos epistemológicos e pedagógicos do Programa. Santos (2011) apresenta uma análise crítica do mesmo, levantando a hipótese de que,

a Licenciatura em Educação do Campo entra em contradição com seu enraizamento nas lutas da classe trabalhadora ao adotar fundamentos teóricos oriundos do escolanovismo e do relativismo epistemológico e cultural que se constituíram em suportes para as reformas da formação de professores levadas a cabo desde os anos 1990 pelas políticas neoliberais. (SANTOS, 2011, p.18).

Diante disto, o autor defende as teses:

1. As formulações hegemônicas em educação sintetizadas no lema "aprender a aprender", divulgadas pela ONU/UNESCO/UNICEF e Banco Mundial, têm transpassado os círculos intelectuais do pensamento pedagógico de esquerda com o discurso sedutor da educação para a diversidade, a cotidianidade, os saberes espontâneos e locais em detrimento da máxima apropriação do conhecimento pelas camadas subalternas da sociedade. Os projetos da Licenciatura em Educação do Campo têm incorporado esses princípios e orientado a formação de professores, em termos de fundamentação teórico-metodológica, àquele ideário. Diante dessa afirmação, impõem-se como necessidade a crítica rigorosa a esses ideários, articulada à construção de proposições superadoras na formação dos educadores no campo ou cidade. 2. A categoria da "universalidade", na perspectiva do Marxismo e das formulações da Pedagogia Histórico-Crítica, apresenta-se como resposta diametralmente oposta às proposições escolanovistas/relativistas e um vigoroso suporte na luta contra o esvaziamento da formação do educador. Desta feita, a defesa de uma formação de professores que valorize a transmissão/apropriação do conhecimento em suas formas mais ricas e universais na educação escolar é essencial para o desenvolvimento dos indivíduos singulares, assim como para o avanço da organização das lutas da classe trabalhadora em direção à possível emancipação da humanidade. (SANTOS, 2011, p.20). 
Verificamos através das análises de Santos (2011), que as críticas operadas por Duarte (2003) e por nós neste texto, têm uma necessidade real (não são meras análises de teorias ou de idéias), uma vez que as ideias aqui criticadas estão sendo veiculadas e apropriadas pela classe trabalhadora para suprir uma necessidade concreta que é a elevação de seu padrão cultural, o que contraditoriamente, por meio das teorias do 'professor reflexivo', não irá ocorrer. Pesa também a análise de Duarte (2003) acerca dos pressupostos pedagógicos de Perrenoud, que se vincula ao ideário escolanovista, às pedagogias ativas, o que demonstra que a teoria do professor relflexivo está para o professor, assim como a já demonstradas "pedagogias do aprender a aprender" estão para os alunos. Além disto, o autor demonstra que os estudos no campo da 'epistemologia da prática' e do 'professor reflexivo' estão fortemente impregnados dos temas e das abordagens próprios do universo ideológico neoliberal e pós-moderno. (DUARTE, 2003, p. 611). Esta observação se torna extremamente importante, porque como apontou Caldart (2010) e Santos (2011), a 'Educação do campo' está enraizada nas lutas da classe trabalhadora, e como tal, é pressuposto que defendesse não as incertezas, o fim das metanarrativas, o fim da história, o individualismo etc., mas sim, operasse com base nas premissas teóricas e programáticas da classe trabalhadora pautadas na defesa do fim da propriedade privada dos meios de produção e da exploração do homem sobre o homem.

Isto significa que, no âmbito das teorias educacionais e pedagógicas, os trabalhadores necessitam apropriar-se do valor positivo do conceito de trabalho educativo, no qual cabe ao processo educativo dirigir o desenvolvimento psíquico do indivíduo e não caminhar a reboque de um desenvolvimento espontâneo natural. (DUARTE, 1998, p.5). A negação aos movimentos de luta social de teorias fundadas nas necessidades históricas dos trabalhadores, como o são a pedagogia socialista e a pedagogia histórico-crítica, deixa um campo aberto para se pensar que as teorias do 'aprender a aprender' e do 'professor reflexivo' são as únicas a existirem e que apresentam a possibilidade de uma resposta ao problema colocado. Este fato concreto impõe uma responsabilidade ainda maior às direções políticas neste momento histórico. Em nossa análise colocar nos ombros dos trabalhadores da educação do campo a responsabilidade por sua formação é o papel que cumpre estas teorias, e que somente de posse de uma teoria que tenha sido elaborada para enfrentar o problema da formação de professores com radicalidade ajudará no avanço das conquistas da classe trabalhadora por meio do 'trabalho educativo'. Neste sentido estaremos apontando nas conclusões possibilidades identificadas em estudos que apresentaram antíteses ao pensamento hegemônico veiculado nas teses e dissertações.

\section{Conclusões}

Diante do forte caráter idealista das tendências apresentadas para a formação de professores do campo, buscamos possibilidades de essência para a produção do conhecimento que se contraponha à tese hegemônica do professor reflexivo. Estas foram identificadas a partir da análise de uma amostra de 20 estudos em nível de doutorado dentre o total de 98 que apresentam antíteses às teses hegemônicas veiculadas no conjunto dos 433 estudos analisados.

A principal dessas possibilidades de elaboração teórica com base materialista é a consideração da categoria modo de produção, na pesquisa sobre a educação dos trabalhadores do campo. Segundo Marx, 
[...] na produção social da sua existência, os homens estabelecem relações determinadas, necessárias, independentes da sua vontade, relações de produção que correspondem a um determinado grau de desenvolvimento das forças produtivas materiais. $\mathrm{O}$ conjunto destas relações de produção constitui a estrutura econômica da sociedade, a base concreta sobre a qual se eleva uma superestrutura jurídica e política e a qual correspondem determinadas formas de consciência social. O modo de produção da vida material condiciona o desenvolvimento da vida social, política e intelectual em geral. Não é a consciência dos homens que determina o seu ser; é o seu ser social que, inversamente, determina a sua consciência. Em certo estágio de desenvolvimento, as forças produtivas materiais da sociedade entram em contradição com as relações de produção existentes ou, o que é a sua expressão jurídica, com as relações de propriedade no seio das quais se tinham movido até então. De formas de desenvolvimento das forças produtivas, estas relações transformam-se no seu entrave. Surge então uma época de revolução social. A transformação da base econômica altera, mais ou menos rapidamente, toda a imensa superestrutura. (MARX, 1987, p. 24-25).

O exceto acima explicita a necessidade fundamental da categoria modo de produção nas pesquisas sobre a educação dos trabalhadores do campo: identificar as determinações concretas que na atualidade, impõem à Educação do Campo uma tarefa revolucionária, a saber, acirrar as contradições entre as forças produtivas e as relações de produção por meio da transmissão do conhecimento objetivo que humaniza o homem, sem o que esta proposição nascida no seio das lutas da classe trabalhadora, adquire um caráter contra revolucionário. Destacar que não se trata de atribuir à educação uma tarefa que não lhe cabe, nos aproximando de uma vertente não-crítica, mas de verificar as condições para que ela cumpra sua função social em um contexto de crise estrutural do modo de produção do capital.

A consideração dos elementos concretos do modo de produção e sua expressão no campo indicam a possibilidade de avanço na compreensão acerca do que vem se denominando de antagonismo entre campo e cidade, que veicula a ideia de que trabalhadores do campo e da cidade são diferentes, e portanto, devem ter formações específicas, baseadas nas suas culturas, nos seus cotidianos. Em nossa análise, este é o ponto nevrálgico que explica a educação que é proporcionada para os trabalhadores do campo e da cidade. Nos estudos analisados, ao contrário, considera-se a contradição entre campo e cidade, baseada na articulação entre: a burguesia agrária brasileira e o capital internacional; os grandes monopólios econômicos aliados ao Estado e os representantes do latifúndio; o contexto mundial com uma nova divisão internacional do trabalho caracterizada, cada vez mais pela presença de blocos regionais, por uma grande importância das empresas multinacionais no comércio mundial, o que tem levado à expansão do latifúndio e às dificuldades cada vez maiores da continuidade de inúmeros estabelecimentos agrícolas no Brasil, com um número significativo destes desaparecendo a cada ano.

Desta forma, os estudos consideram a reorganização do campo a partir da perspectiva do agronegócio, na qual: os camponeses, produtores de alimentos e matériasprimas, estão submetidos ao assalariamento, ou seja, tem sua força de trabalho tão explorada quanto os operários urbanos, e estão sujeitos a problemas sociais semelhantes aos da cidade; a modernização aumenta as exigências e diminui o período de ocupação da força de trabalho não qualificada numa propriedade agrícola, substituindo o trabalhador permanente pelo volante temporário, impondo o assalariamento na sua forma mais 
perversa de exploração: trabalho temporário, diarista, em carteira assinada e sem direitos e garantias; a relação existente entre a industrialização da economia e do agro que, de um lado, reduz a quantidade de mão-de-obra na agricultura em alguns setores e, de outro, aumenta o número de agricultores frente à necessidade de industrialização da agricultura, haja vista a exigência de produção ao menor valor possível, uma vez que as mercadorias têm que ser realizadas no mercado capitalista; considerando o meio rural, este processo evidencia-se na difusão de novas tecnologias e modos de produção, também caracterizados por crescimento do trabalho morto na indústria de insumos (sementes, agrotóxicos, fertilizantes, máquinas, tratores etc.) e da utilização de somas de capitais nacionais e internacionais para a produção de commodities, produzidas freqüentemente por multinacionais e voltadas para o mercado externo.

As teses analisadas demonstram claramente que $o$ fundamento real da contraposição entre o campo e a cidade é a contradição entre o capital e o trabalho, que nas teses hegemônicas acerca da formação de professores é reduzida às diferenças culturais entre campo e cidade, ocultando e negando a história e a luta de classes. No campo, assim como na cidade, o capital necessita de trabalhadores que se submetam as transformações técnicas constantes e ao acúmulo de funções proporcionado por esta nova composição, ou ainda, que se submetam a trabalhos degradantes que não exigem nenhum grau de instrução, desenvolvidos em curtos períodos no ano.

Para dialogarmos com a particularidade do campo, é necessário por outro lado, verificar qual é a tendência da composição do capital na realidade atual do modo de produção e sua expressão campo brasileiro, sem o que não é possível compreender a educação que é oferecida aos trabalhadores do campo, as formas de resistência em curso, nem contribuir na construção destas resistências. A formação dos professores tem no modo de produção sua base concreta, cuja consideração é o primeiro ato para trazer a formação ao mundo real dos trabalhadores do campo.

\section{Referências}

BRASIL, Ministério da Educação, PDE. $O$ que foi Feito. Disponível em: http://gestao2010.mec.gov.br/o_que_foi_feito/program_151.php. Acessado em 27 de Julho de 2011.

CALDART, R. S. Educação do campo: notas para uma análise de percurso. In: MOLINA, M. C. (Org.). Educação do Campo e Pesquisa II: questões para reflexão. Brasília: MDA/MEC, 2010. Pp. 103-126.

DUARTE, N. Conhecimento tácito e conhecimento escolar na formação do professor (Porque Donald Schön não entendeu Luria). In: Educação e Sociedade, Campinas, vol.24, n.83, pp.601-625, agosto de 2003.

ENGUITA, M. F. Trabajo, escuela e ideologia. Madrid: Ediciones Akal S.A., 1985.

MARX, K. Prefácio da Contribuição à crítica da economia política. In: MARX, K. Contribuição à crítica da economia política. 2.ed. São Paulo: Martins Fontes, 1987.

ROSSET, P. O bom, o mau e o feio: a política fundiária do Banco Mundial. In: MARTINS, M. D. O Banco Mundial e a Terra: ofensiva e resistência na América Latina. São Paulo: Viramundo, 2004.

SÁNCHEZ GAMBOA, S. A. Pesquisa em educação: métodos e epistemologias. Chapecó: Argos, 2007. 
SANTOS, C. E. F. dos. Relativismo e Escolanovismo na formação do educador: uma análise Histórico-Crítica da Licenciatura em Educação do Campo. Universidade Federal da Bahia. Tese. 2011.

Notas

${ }^{1}$ Texto apresentado no painel intitulado Crítica da produção do conhecimento à luz das determinantes do modo de produção: contribuição ao debate da formação de professores em pedagogia e educação do campo durante o XVI ENDIPE - Encontro Nacional de Didática e Práticas de Ensino, realizado na Universidade Estadual de Campinas (UNICAMP) no ano de 2012.

${ }^{2}$ LEPEL UFAL - Campus Arapiraca 